\title{
Aristoteles’te Müzikal Terimlerin Anlamı ve Kullanımı
}

\author{
Öz
}

$\mathrm{Bu}$ çalışmanın amacı, Aristoteles'in kullandığı temel müzikal terimlerin günümüz terminolojisi ile karşıllaştırılarak açılanmasıdır. Burada, müzik, Aristoteles'in sanat anlayışı içerisindeki yeriyle birlikte alınmaktan ziyade, teknik bir konu olarak işlenecektir. İzleyeceğimiz yöntem, öncelikle, Greklerden elimize ulaşan müzikolojik veriler 1şı̆̆ında teknik terminolojiyi netleştirmek; daha sonra Aristoteles'in metinlerinden yola çıkarak ve Platon'un söz konusu terimleri kullanımları ile karşılaştırmalar yaparak, konu ile ilgili terimlerin kullanımının işaret ettiği müzik anlayışını öğelerine ayıracak bir metin analizi yapmak olacaktır. Temel metinlerimiz Poetika ve Politika olmak üzere, gerekli noktalarda Retorik ve Metafizik'teki ve kullanımları da hesaba katacağız.

\section{Anahtar Kelimeler}

Müzik, Tonal Müzik, Melodi, Armoni, Ritim.

\section{The Meanings and The Usages of Musical Terms in Aristotle}

\begin{abstract}
The aim of this paper is to explain the basic musical terminology used by Aristotle comparing with today's. Rather than taken in relation with the philosopher's understanding of art, music will be taken as a technical subject. The method will be, clarifying the technical terminology of the ancient Greeks by the ancient texts, thereafter making a text analysis which will focus on the usages of the terms by Aristotle, referring to Plato. The main texts will be On Poetics and Politics, but Rhetoric and Metaphysics will also be used when needed.
\end{abstract}

\section{Keywords}

Music, Tonal Music, Melody, Harmony, Rhythm. 


\section{Giriş}

Günümüzde müzik alanında kullanılan temel terminolojinin önemli bir bölümü Antik Yunan kökenlidir. Ancak bu terimlerin antik kullanımları için konuşacak olursak, onların içerisinde işlev ve anlam kazandığı dizge bugünkü ile bir ve aynı değildir. Özetle söylemek gerekirse, günümüz çoksesli müziği, Antik Yunan'da karş1lığı olmayan, seslerin eşit bölümlenmesi fikrini temel alan tampere sistemi, orkestraorkestrasyon yönelimi ve bilimsel temelli ses fiziği çalışmalarının verilerini içerme ve aşma gibi özgün tarihsel koşullar içerisinde şekillenmiştir. Uyumlu aralıklar - uyumsuz aralıklar gibi daha genel terimlerin kapsamlarının değişmesi gibi daha az sorunlu örneklerin yanında, antiklerle armoni anlayışlarımızın benzeşmemesi gibi çok daha dikkat çekici sorunlar hesaba katıldığında, terminolojinin gözden geçirilmesinin sağlayacağı katkılar daha anlaşılır olacaktır.

$\mathrm{Bu}$ çalışmanın dar kapsamında, bu doğrultuda öncelikle Antik Yunan kültürünün bir parçası olarak dönemin müzik anlayışlarının ve müzikoloji çalışmalarının kısa bir özetini sunacağız. Sonrasında Aristoteles'in Poetika ve Politika gibi müzikle ilgili daha detaylı tartışmalara girdiği iki temel metnindeki başlıca müzikal terimleri yer yer Platon'un kullanımlarına dönerek inceleyeceğiz.

\section{Antik Yunanda Müzik}

Antik Yunan'da müziği performatif bir etkinlik konusu ya da teknik bir inceleme konusu olmasının yanında felsefenin bir konusu olarak ele alan en tutarlı ve kapsamlı görüş Platon'a aittir. Platon Devlet'in ilk kitaplarından Yasalar'a varıncaya kadar genel olarak sanatın ve özel olarak müzik sanatının etik ve politik angajmanı sorunsalını hakikat ile ilgisinde ele alarak çağcılları arasında özel bir yer edinir. Devlet'teki sinıflandırmaya göre, benzetmeye dayalı sanatlarla uğraşan ozanlar ve ressamlar, "benzetmeci, benzettiği şeylerin ne olduğunu pek bilmediği" için hakikate üç derece uzaktır. Yapma sanatının ehli "kaval yapan" ve kullanma sanatının ehli "kaval çalan" ise, bu kıyasta, sanatlarının bilgi ile ilgileri bakımından kabul edilebilir durumda sayılır. (Platon 1962: 601-602) Bir sanat dalı olarak müzik ise özellikle yeni nesillerin eğitim sürecinde diğer dalların yanında özel bir amaca hizmet eder. Platon'a göre "[h]içbir şey insanın içine ritim ve düzen kadar işlemez. Müzik ĕgitimi gereği gibi yapıldı mı insanı yüceltir, özünü güzelleştirir. Kötü yapılınca da bunun tersi olur” (1962: 401-d) Bu sebeple, gençlerin bedenleri için jimnastik ne denli önemliyse, kafa eğitiminde de müzik en az o kadar önemli sayılmalıdır. (1962: 424-a) Bu noktada Platon'un önerisi, müziğin üç temel bileşeninden ikisinin, ritim ve makam unsurlarının gözden geçirilerek bunların hangilerinin kullanılacağına karar verilmesidir. Lydia ve Ionia gibi dinleyeni hüzünlendiren makamlar ve bunları çalmaya yarayacak flavta gibi çok telli sazlar kullanılmamal1; bunlar yerine biri barışta kullanılacak yumuşak bir makam, diğeri savaşta kullanılacak sert bir makam olmak üzere iki makam belirlenmeli ve bunlar için lir ve kithara kullanılmalıdır.( 1962: 398-401) Müziğin Apolloncu ölçülülük, düzen ve güzellik yolunda bu tür pratik belirlenişi devletin bekçileri tarafindan sıkı sıkıya denetlenmelidir. Öyle ki Platon’a göre “müzikte yol değişti mi, devletin anayasası temelden sarsllır." (1962: 424) 
Platon Devlet'te sunduğu müzikal terminolojiyi ve teknik ayrımları Yasalar'da da çoklukta devam ettirir. Burada konu açısından temel farklılık, Musalar ve Apollon aracılığıyla yeni nesillerin hangi kurallar doğrultusunda eğitileceğinin ve bu eğitimin ne tür bir pedagojik yöntem ile yapılacağının temel konular olmasıdır. (Platon 1998: 654) Öyle ki, Platon’a göre yasa koyucunun, gençleri neye inandırarak kentte en büyük iyiliği sağlayabileceğini özel olarak belirlemesi gerekir: "Böyle bir topluluğun şarkılarında, masallarında ve sözlerinde her zaman, tüm yaşamı boyunca bu konuda olabildiğince tek ve aynı şeyi söylemesi için her türlü çareyi bulmalıdır.” (1998: 664-a) Çocuklar için "şarkı" formunun seçilmiş olmasının nedeni, onların "uyum" sağlayacak çabayı gösteremeyecek çağda olmalarıdır; onlara anlatılmak istenenin onların hoşlanacakları, "büyüleyici” bir form içerisinde verilmesi uygun olacaktır. (1998: 659e) Nomoi teriminin hem yasaları hem de belirli toplumsal koşullarda birlikte söylenen ezgileri imlediği hesaba katıldığında, buradaki uygulamanın, yasaların müzik aracılığıyla benimsetilmesi olduğu anlaşılır olacaktır. Dahası, bu, sadece çocukları kapsayacak bir uygulama değildir. Üç tür koro olmalıdır: Musalara adanmış çocuk korosu, 30 yaş altındakilerden oluşan tanıklık ve birlik çağrıcısı koro ve 30-60 yaş aralığındaki yurttaşlardan oluşan üçüncü bir koro. (1998: 664) Sanatçılar, devletin talebi yönünde, erdemli yaşamı övecek sözlere sahip ezgileri ritim ve uyum içinde yaratmaya ikna edilerek istenen türde şarkıları yapmaları sağlanacak, ikna edilemezse zorlanacaktır. (1998: 660-a)

Platon dışında Antik Yunanların müzik ile teorik ilgileri, daha ziyade teknik incelemeler düzeyinde kalır. Dönemin, Pythagoras, Aristoksenos ${ }^{1}$ Öklid ${ }^{2}$ gibi önde gelen yazarlarından kalan fragmanlardan ve ikincil kaynaklardan ${ }^{3}$ öğrendiğimiz kadarıyla, müzik üzerine yapıtlar üç genel konu etrafinda toplanmaktadır: Müzik üzerine, armonikler üzerine, müzik üzerine genel bilgiler. Pratik kullanımlarını şimdilik bir yana birakırsak, bir bilgi konusu olarak "müzik", Antik Yunanda, matematik üzerinden anlaşılmaktaydı. Ses aralıklarının matematiksel oranları üzerine gelişen çalışmalar, bu oranların melodik uygulamalarıyla birlikte, müziğin teknik terminolojisinin de gelişmesini sağlamıştır. Öte yandan, özellikle vurgulamamız gereken bir nokta vardır ki, geleneksel Yunan müziğinde "melodi” ön plandadır. Antik Yunan için, Barok dönemden bu yana Batı Müziğinde kullanılan modern armoniden yahut yirminci yüzyılda kullanılmaya başlanan işlevsel armoniden bahsetmemiz mümkün değildir. Aşağıda inceleyeceğimiz iki geleneğin teknik kullanımları bir yana, genel olarak “armoni”den anlaşılan, sesler arasındaki uyumdur. Bu nedenle, dönemin kuramcılarının ilgisi, seslerin aralıkları ve bu aralıkların oluşturduğu dizi kalıplarının incelenip düzenlenmesi üzerinedir.

1 Aristoteles'in bilinen öğrencilerinden ve müzik üzerine Aristotelesçi bilim anlayışını uygulamaya çalışmış bir filozoftur. Lise'de müzik üzerine çalışmalar yapmış, fakat Aristoteles'in Lise'nin yönetimini kendisine bırakmaması üzerine burayı terk etmiştir. George Grote, Aristoteles'in Politika'nın 1342-a numaralı pasajında “çağdaş müzisyenler" ifadesi ile Aristoksenos'u kastetmiş olabileceğini belirtir. (Grote 2004:178)

2 Batlamyus da genellikle bu gelenek içerisinde ele alınır.

3 İkincil kaynakların kısa bir listesi kaynakça içerisinde verilmiştir. 
Antik dönemde etkili olmuş iki ana müzikoloji geleneğinden söz edilebilir: Sayı gizemciliği üzerine kurulu Pythagorasçı gelenek ve Aristotelesçi çizgiyi takip eden Aristoksenosçu gelenek. (Mahthiesen 2006: 120) Pythagorasçı gelenekte müzik bağımsız bir araştırma alanı olmanın gerisinde, matematik ve sayı gizemciliği açısından ele alınmıştır. Pythagorasçılar doğada ve diğer insan etkinliği alanlarında olduğu gibi müzikte de aritmetik ve geometrik mükemmelliğin izlerini aramış ve müziği doğa yasalarının ve yaratıcı insan etkinliğinin örtüştüğü bir yaratım alanı olarak incelemiştir. Müziği ağırlıklı olarak teknik açıdan inceleyen bu bakış açısı Platon'un kendilerine yönelik "[H]epsi için kulak kafadan önce gelir" şeklindeki eleştirisinden kaçamamıştır. (Platon 1962: 531-a)

Pythagorasçı geleneğin, başlangıcının Pythagoras'ın 7 telli kithara üzerinde yaptığı çalışmalara dayandığg rivayet edilir. Hatta, bu çalışmaların sonucu olarak, Pythagoras'ın, 8 telli bir kithara yaptığı da söylenegelir. Onun, tel uzunluğu ve aralıklar üzerine çalışmalarında elde ettiği sonuçlar şunlardır: 12 birimlik bir tel ikiye bölünerek $o k t a v^{4}$ elde edilmiştir. Elde edilen altı birimlik tel uzunluğu 12 birimlik uzunluğun bir oktav tizidir. 8 birim uzunluğundaki tel ile 5 'li aralığ, 9 birim uzunluğundaki tel ile 4'lü aralığı bulmuştur. Art arda dizilmiş dört seslik aralık tetrakord (dört tel) olarak adlandırılmış ve müzik teorisinin temeli olarak kabul edilmiştir. Telin 8/9'u ile bir tam tonu elde eden Pythagoras, bir notaya 6 kere tam ton ilave ettiğinde yaklaşık olarak o notanın oktavını elde etmiştir. (Eraydın 2006: 22) Müzikal aralıklar, "Pythagoras Lambdası" adı verilen çizelge aracılığıyla, oranların belirlediği aralıkları açıklamak için kullanılmıştır. Buna göre, iki tel arasındaki $2 / 1$ 'lik oran 1 oktavı, 4/1'lik oran 2 oktavı, $8 / 1$ oran üç oktavi, $3 / 1$ oran 1 oktav ve üç tam+bir yarım sesi, 9/1 oran 3 oktav ve bir tam sesi, 27/1 oran 4 oktav ve dört tam+bir yarım sesi vermektedir. (Mahthiesen 2006: 115)

Aristoksenos'un bu konudaki çalışmalarının önemi ise iki yönlüdür: Öncelikle, müzik tarihinde bilinen en eski sistematik kuramsallaştırma çabası, kaynakları Pythagoras'1n belli başlı terimleri olmakla birlikte, Aristoksenos tarafından gerçekleştirilmiştir. Aralık, dizi, ton, melodi, dissonans, konsonans ${ }^{5}$, ses pozisyonları, melodik ifade, devamlılık, kompas $^{6}$, modülasyon $^{7}$ gibi terimler bu geleneğin ürünleridir. (Mahthiesen 2006: 120) Ayrıca, tüm parçaları elimize ulaşmış, müzik hakkında bilinen en eski teori kitabı Armonikler ${ }^{8}$ de yine Aristoksenus'a aittir. ${ }^{9}$ İkinci olarak,

4 “Oktav”, art arda dizili sekiz sesin oluşturduğu bütünlüktür. Notaların ilerleyiş düzeni Mod 7'ye göre yapılmaktadır, yani 8. ses 1. ses ile aynı isme sahiptir.

5 Konsonans, "uyumluluk" anlamında kullanılan bir müzik terimidir. Melodik veya armonik uyum için kullanılmaktadır. Fakat buradaki kullanımı melodik bağlamdadır. Benzer şekilde dissonans da "uyumsuzluk" anlamında kullanılır.

6 Kompas, dans ve müzikte "ritim sayacı" anlamına gelen bir müzik terimidir.

7 Modülasyon, eser içerisinde ton aktarımı anlamına gelmektedir. Türkçeye genellikle göçürüm olarak tercüme edilir.

8 Bir bilim olarak “harmonics”in konusu, müzikal uyumluluğun ilkeleridir. Aristotelesçi yönteme uygun olarak, burada, ilkin konu belirlenir, daha sonra bu konu öğelerine ayrılır, bu öğeler tek tek incelenir. Ve sonunda, öğelerin en yetkin kullanımın olanaklarına göre, konusunu en başarılı gerçekleştirmenin ilkeleri verilir. (Katz, Ruth and Dahlhaus 1987: 271272) 
Aristoksenos, Pythagoras'ın göz merkezci, oran ve hesaba dayalı yönteminin yerine, kulak ve duymanın merkezde olduğu işitsel yöntemi kullanmıştır (Aristoxenus Tarentum 1902: 14-15). Böylece, teknik hesapların yeniden, kulak merkezli yapılmasının gerekliliği ortaya çıkmıştır. (1902: 43) Bu uygulama ile değişenlerin başında, aralıkların hesabı gelmektedir. Pythagoras'a göre, oranlarla yapılan ton (tam ses) aralığı, Aristoksenos'a göre bir sesin dörtlüsü ve beşlisi arasındaki fark kadardır. $\mathrm{Bu}$ yönteme göre tam ses aralığının hesaplanması, bugün bile, uygun ve ölçülebilir bir sonuç vermektedir; üstelik iki telli basit bir çalg1 üzerinde her zaman rahatlıkla test edilebilir bir yöntemdir bu. ${ }^{10}$

Pythagoras'a atfedilen tetrakord, yani art arda dizilmiş dört seslik aralık, aslında kitharanın akorduyla ilgili bir düzene işaret eder. Tetrakord terimi "dört tel" anlamına gelir ve art arda dizili dört sesin diziliş düzenini anlatmak için kullanılır. Üç tür tetrakord vardır: Diatonik $(1+1+1 / 2)$, kromatik $(3 / 2+1 / 2+1 / 2)$ ve enharmonik $(2+1 / 4+1 / 4) .{ }^{11}$ İşte bu dizilerin farklı birleşimleri, farklı çeşitli müzikal yürüyüş kalıpları verir bize. Bu kalıplar, Türkçede makam, gam, dizi dediğimiz, ezginin hangi notalar kullanılarak çalınacağını belirleyen kalıplardır. Antik dönemde söz konusu müzik geleneğinde bu kalıplar için harmonia terimi kullanılmaktaydı. Bu dönemden kalma, içerisinde bu kalıpların birbirine kurallı bir bağlanışının görüldüğü aşağıdaki tablo, makamlar üzerine müzikal hesaplamaların yapılabilmesine yaramaktaydı. Bu tabloda görünen müzikal dizgeye, müzik terminolojisinde, Yunan Kusursuz Dizgesi ad1 verilmektedir. (Aristoxenus Tarentum 1902: Introduction)

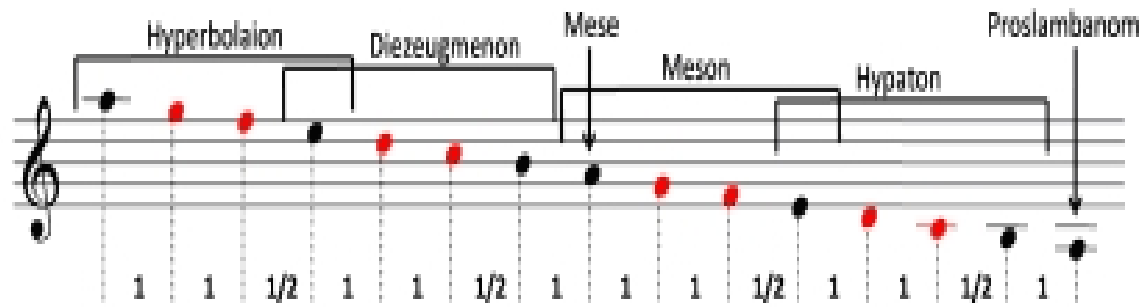

Bir müzikal kompozisyonda ya da bir müzikal icrada yapılan, harmonia kalıplarından birinin belirlediği sınırlar içerisinde, belli notaları seslendirmektir. $\mathrm{Bu}$ türlü üretilen ses dizisine basitçe melodi veya ezgi denir. Terimin bugünkü kullanımında, köken ve anlam açısından büyük bir farklılık ya da anlamsal kayıp söz konusu olmamıştır. Grek müziğinde de aynı anlamı karşılayacak şekilde melos terimi kullanılmaktaydı. Öte yandan, bir ezginin anlamlılığın ölçütü, onun makamla uyumluluğu olmakla birlikte, uyumluluk kendisini seslerin zamansal art ardalığında gösterir. $\mathrm{Bu}$ art ardalığın uyması gereken zamansal ölçülere/kalıplara da yine

9 Ancak, bu eserin basımı ilk kez 16. yüzyılda yapılmıştır.

10 İki telden biri diğerinin dörtlüsü olacak şekilde akort edildiğinde, aynı zamanda ikinci tel birincinin beşlisi olur. Dolayısıyla, bir "dörtlü" ve bir "beşli" aralığın oranları bu kadar basit bir yolla edinilebilir. (Aristoxenus Tarentum 1902: 46) 
bugünkünden farklı olmamak üzere rhuthmou adı verilirdi. Bu, Türkçede, her ne kadar farklı kalıplar içerisinde gerçekleşiyorsa da, ritim veya usul olarak karşılanmaktadır. Ritim/rhuthmou, ezgi boyunca tekrarlanan döngüsel bir kalıptır.

Son olarak, belli bir makamda, ritimde icra edilen melodiye eşlik eden bir diğer unsur sözdür (logos). Fakat bu unsurun müzikteki yeri hakkında, özellikle Platon ve Aristoteles farklı görüşlere sahiptir. Bu tutum farklılığının Poetika ve Politika gibi iki ayrı konu üzerine olan kitaplarda görünmesi dolayısıyla, iki kitabı ayrı ayrı ve Platon'un terminolojik kullanımlarıyla ilgilerinde incelemekte fayda vardır. Bu noktada, varsaydığımız terminolojik tutarlılığa dayanak olarak, James Adam'ın Devlet 398-d'ye düştüğü notu hatırlatalım:

Grek müziğinin en iyi döneminde, lirik şiir yalnızca müzik için ve müzik yalnızca şiir için yazılırdı; bu iki unsuru ayırmak uygun görülmezdi. Müziğin unsurları, ritim (rhuthmos) ve armoni (harmonia) idi... Armoni, tiz (oxu) ve pes (baru) seslerin geniş anlamda her türlü uyumudur (homologia). Fakat pratikte, sözcük, özel olarak belli makamlar [scales or modes] için kullanılırdı. Platon da bu terimi burada bu anlamda kullaniyor. (Plato 1902: 398d-e)

\section{Poetika'da Müzik}

Aristoteles, Poetika'da müziği bir sanat olarak değil, bir taklit aracı olarak ele alır. Bunun nedeni, Poetika'da inceleme konusunun genel olarak "ses aracılığıyla taklit eden sanatlar", özel olarak "şiir" (poema)/ "şiir sanatı" (poiêtikê) olmasıdır. Burada, öncelikle şunu belirtmemiz gerekir: Flüt ve kithara ve kaval sanatında sadece harmoni/armoni(harmonia) ve ritmin(rhuthmō) kullanıldığı (Aristoteles Ekim 2008: Bölüm 1.4); buna karşı, ezgili şiirler (yani bugün anladığımız anlamda şarkılar) olan dithyrambos şiiri ve nomonda, ritim (rhuthmô), mısra ölçüsü (metron) ve melodinin (melei) baştan sona dek kullanıldığ1 belirtilmektedir. (Ekim 2008: Bölüm 1.5) Yine başka bir yerde, şiirde ölçünün (metron) de bir tür "ritim" olduğu söylenmektedir. (Ekim 2008: Bölüm 4.1) Dolayısıyla, bu “ezgili şiir” türüne özgü olanın melos öğesi olduğunu hesaba kattığımızda, melosu, "şiire eşlik eden melodi" olarak ele almamız yanlış olmayacaktır. Bu kanıyı destekleyecek ifadelere şu pasajda rastlarız: “...Her bölüm için özel araçlar kullanır” deyince de, kimi bölümlerde yalnız ölçünün (metros), kimi bölümlerde ise müziğin ${ }^{12}$ kullanılmasını anlıyorum.” (Ekim 2008: Bölüm 6.2) Bu ifadeler tragedya türü için kullanılmaktadır. Aristoteles'in burada, tragedyada koro şarkılarının okunduğu bölüm ile düşüncelerin ezgisiz bir şekilde ifade edildiği diğer bölümleri ayırıyor olduğu açıktır. İkinci olarak, Aristoteles, melos terimi ile melopoiia terimini ayrı anlamlarda kullanmaktadır. Her ne kadar Aristoteles "müzik (melopoiia) deyince de herkesin bundan anladığı şeyi anlıyorum" diyerek daha fazla bir açıklama vermese de; diyebiliriz ki, bunlardan ilki, yukarıda bahsettiğimiz anlamda "şiire eşlik eden ezgi" iken, ikincisinin anlamı "müzik yapma/besteleme"dir. Nitekim bu terim,

12 Burada İsmail Tunalı çevirisi şu şekilde: "kimi bölümlerde yalnız ölçünün, kimi bölümlerde ise ayn zamanda müzik ile şarkının kullanılmasını anlıyorum.” Oysa metnin söz konusu pasajında şarkı ve müzik için iki ayrı sözcük kullanılmamakta. Bu nedenle burada kullanılan melousu yalnızca "müzik" olarak çevirmeyi doğru bulduk. 
Kassel ve Benardete çevirilerinde de müzik yapma/besteleme (song-making) olarak karşılanmıştır. (Aristotle 2002: Bölüm 6.3; 6.6; 6.16)

Aristoteles, armoni ve ritmin insan için doğuştan olduğunu söylemektedir. (Aristoteles Ekim 2008: Bölüm 4.1) Öyle ki, harmoni, gündelik konuşma tonumuzda da görülür ve konuşma tonumuz jambik ölçü ile benzerlik içerisindedir. (Ekim 2008.: Bölüm 4.8) Öte yandan, şu ifade ilginçtir: “'Sanatça güzelleştirilmiş dil' deyince, harmoniyi (harmonia), yani şarkı (melos) ve mısra ölçüsünü (rhuthmou) içine alan bir dili anllyorum." (Ekim 2008.: Bölüm: 6.2) Burada, İsmail Tunalı'nın, rhuthmou terimini, dördüncü bölümdeki açıklamaya uygun olarak, mısra ölçüsü kastedildiğini düşünerek bu şekilde çevirdiği anlaşılmaktadır. Bu bir açıdan anlamlıdır: Tragedyadaki dil açısından verilen bu açıklama, "söz"ün merkezde olduğu bir sanat türü içindir. Dolayısıyla "ritm"i, bu sanat özelinde "mısra ölçüsü" olarak düşünebiliriz; bu şekilde, melosun neden "melodi" olarak değil de "şiire eşlik eden ezgi" olarak anlaşılması gerektiği de netleşmiş olur.

Harmonianın bugün anladığımız anlamda makam olarak anlaşılmasının uygun olduğunu belirtmiştik. Nitekim harmonia, Platon'un Şölen diyalogunda da, "tiz ve pes seslerin birlik içerisinde uzlaşması" olarak açıklanmaktadır. (Platon 2006, 187-b) Fakat, Poetika'da, teriminin genel anlamıla "uyum"/"armoni" anlamlarında kullanıldığını belirtmek gerekir. Aksi durumda gündelik konuşma tonumuzun "makamsal" olduğunu söylemek sağduyuya aykırı olurdu. Üstelik, bu konuda, yukarıda alıntıladığımız pasaj bize bir fikir vermektedir: “...Harmoniyi, (harmonia), yani şarkı (melos) ve misra ölçüsünü (rhuthmou) içine alan bir dili anllyorum." (Aristoteles Ekim 2008: Bölüm 6.2) Buradan anlaşılan şudur ki, Aristoteles'in Poetika'da kullandığı anlamda harmonia, ses aracılığıyla taklit eden sanatlar için, genel bir uyum ilkesi olarak da görülmektedir. ${ }^{13}$ Ancak burada bir istisna vardır; Aristoteles, dans için "harmoni olmadan yalnız ritmi kullanır" demektedir; fakat bellidir ki dans, belli bir melodi yahut en azından ritim ile yapılır. (Ekim 2008.: Bölüm: 1.4) Dans Poetika'da işlenmeden kalmış bir konu olduğu için bu nokta belirsizdir; fakat, bunun nedenini iki şekilde tahmin edebiliriz: Öncelikle, Aristoteles, dans unsurunu, dansa eşlik eden müzikten ayrı olarak düşünüyor olabilir.

Harmoni kavramının Antik dönemden uğradığı anlam değişiklikleri üzerine, dünya çapında çok ciddi bir literatür vardır. Özellikle Pythagorasçı geleneğin -Aristoteles’in Metafizik’te haklı olarak eleştirdiği gibi- kuramsal çarpıtmaları ve dolaylı etkileri nedeniyle, teorik ve pratik müzik incelemelerinin bilimsel bir yöntemle yapılması, M.S. 9. yüzyılın ikinci yarısına gelene kadar gerçekleştirilememiş, müziğin kuramsal ilkelerinin pratiğe uygulanmasında sorunlarla karşılaşılmıştır. Özellikle, manastır eğitiminde, öğrencilerin birlikte ilahi söylemeleri noktasında ortaya çıkan sorunlar, "uyumlu aralıklar"/"uyumsuz aralıklar" konusunda kuramsal mükemmellikten vazgeçilip pratik sonuca yoğunlaşılması gerekliliği doğurmuştur. (Bknz: Musica Enchiriadis ve Scolia Enchiriadis) Nihayet, 15. yüzyıla geldiğimizde, bu yönde yapılan çalışmalar sonucu, Yunan geleneksel müziğinden oldukça farklı bir noktaya varılmıştır. Bu dönemden 19. yüzyıla kadar, üçlü aralıklar üzerine kurulu bir armoni sistemi olan "üçlüsel armoni” kullanılmıştır. Geçirilen dönüşüm içerisinde, terimler sabit kalmakla birlikte, birçoğunun anlamı ve kuramsal zemini değişmiştir. Özellikle bugün hala Antik Yunan müziğine dayandırılan armoni kavramı, Antik dönemde zamansal art ardalığa dayalı tek sesli uyumu anlatırken; 20. yüzyıla gelene kadar, bunun anlamı, eş zamanlılığa dayalı çok sesli orkestral uyum halini almıştır. Bu karşıtlıkla ilgili olarak bknz: Rousseau 2009: 57-68, 79-85 
Öte yandan, Antik Yunan müziğindeki enstrüman çeşitliliği içerisinde vurmalı çalgıların yok denecek kadar az olması ve müzikoloji çalışmalarının büyük kısmının telli enstrümanlar üzerine yapılıyor olması, vurmalı çalgılarla yapılanın bağımsız bir müzik türü olarak kabul edilmediğine yorulabilir.

\section{Politika'da Müzik}

Politika'da, müzik, okuma-yazma, beden eğitimi ve her zaman olmamakla birlikte, resim çizme, eğitimin temel dört konusunu oluşturur. Yani, Poetika'dan farkl1 olarak, burada müzik, bir eğitim konusu olarak ele alınmaktadır. (Aristoteles 2000: 1337-b) Öte yandan, yine Poetika'dan farklı olarak, müzik (mousikês) ve şiir (poiêtôn) ayrı sanatlar, insanların haklarında yargı belirttikleri iki ayrı konu olarak ele alınmaktadır. (2000: 1281-b) Bu, şüphesiz, aynı konunun iki kitapta ele alınış bağlamıyla ilgili bir farktır. Öyle ki, daha evvel söylediğimiz gibi, Poetika'da bir taklit arac1, tragedyanın bir öğesi olarak incelenen müzik, temel bir öğeden dahi sayılmamakta, yalnızca, tragedyanın "şarkı besteleme" ile ilgili bir unsuru olarak düşünülmektedir. Politika'da ise, esas olarak, “müzik”, melodik, ritmik ve armonik yönleri ile, şarkı söyleme ve enstrüman çalma açısından, bütünlüklü bir sanat olarak incelenmektedir.

Burada önemli olan bir diğer farklılık da, "müzik" için mousikês teriminin kullanılıyor oluşudur. Müzik sanatının kapsamına nelerin girdiği şu pasajda açıklanmaktadır:

Biraz da, şu harmoniler (harmonias) ve ritimler (rhuthmois) ve eğitimle ilişkileri sorununu incelemeliyiz. Bütün harmoni ve ritimlerden yararlanacak mıyız, yoksa aralarında bir ayrım gözetecek miyiz? Sonra, aynı ayrım eğitime ilişkin olarak kullanılacak mı, yoksa bir üçüncü grup mu ayıracağız? Besbelli, müzik (mousikên), bildiğimiz biçimiyle melodi (melopoiias) ve ritme (rhuthmôn) bölünmektedir; bunlardan her birinin eğitim üstünde nasıl bir etkisi olduğunu ve iyi bir melodisi olan müziği (tên eumelê mousikên) mi, yoksa iyi bir ritmi olan müziği (ten euruthmon) mi daha yüksek sayacağımızı düşünmeyi atlamamalıyız. (2000: 1341-b)

Harmoni unsurunun, burada, müziğin kapsamına alınmamış olmasını, yukarıda, harmoni ve melodi ilişkisinde yaptığımız açıklamaya dayanarak; bu ayrımın aslında müziğin pratik uygulamasında duyulanın ne olduğuyla ilişkilendirildiği şeklinde düşünebiliriz. Yani, melodi, örneğin Lydia, Mixolydia gibi harmonilerin/gamların birine uygun olarak yapılan seslendirme veya icradır. Harmoni ise, bu melodilerin uygun olmaları beklenen kalıplardır. Müziğin teorik analize müsait olan kısmı, harmonidir. $\mathrm{Bu}$ nedenle, Aristoteles, burada melodiyi müziğin temel iki unsurundan biri olarak saymaktayken, yine Politika'da, müziğin melodik yönüyle ilgili incelemede harmonileri ele almaktadır. $\mathrm{Bu}$ yargımızı destekleyecek ifadelere 8. kitabın 7. bölümünde rastliyoruz: “...bu gibi şïrler, kendilerine yakışan anlatımı Phyrg makamında bestelenmis melodilerde bulurlar. Örneğin, dithyrambos türü şiiri herkes Phrygiambos sayar... özellikle, örneğin Philoksenos efsanelerini Dor makamında dithyrambos olarak yazmaya kalkmış ama böyle yapamamıştır.” (2000: 1342-b) 
Diğer taraftan, Poetika'da "söz" merkezli bir inceleme yapılmakta iken, Politika'da "söz"ün müziğin unsurlarından biri olarak sayılmadığı görülmektedir. Platon'un Devlet'te yaptığı şu tanımı hatırlayalım: "Melodi (melos) üç şeyin karışımıdır: Söz (logou) $)^{14}$, makam (harmonias), ritim (rhuthmou)." ${ }^{15} \mathrm{Bu}$ farkl1lık, Devlet’te ve Politika'da müzik incelemesinin genelinde de görülmektedir. Platon, bu konuya, özellikle mit ve nazım türünden eserleri eklemektedir. (Platon 1962: 398-d) Benzer şekilde, Yasalar'da da, çocuk, genç ve orta yaşlılar için üç tür koro olması gerektiği söylenirken, bu koroların işlevi hakkında, ilahilerin sözel etkileri üzerinde durulmakta, melodik yönlerinin ise etkiyi arttırma amaçlı olması gerektiği belirtilmektedir. İkinci kitabın neredeyse tamamı, söz ve melodi arasındaki bu dengenin nasıl kurulacağ üzerinedir. Özellikle şu pasaj, bu dengede, sözün önemini açılar niteliktedir:

\begin{abstract}
"Çünkü bunların hepsinin karmakarışık edildiğini görürler; üstelik ozanlar çıplak sözleri vezne yerleştirerek ya da ezgi ve ritmi sözsüz ele alarak, salt kithara ve flavta kullanarak ritim ve figürleri ezgiden ayırıyorlar: Böylece bunlarda söz olmadığından ritmi ve harmoniyi yakalamak, ne demek istediğini ve söz etmeye değer taklitlerden hangisine benzediğini anlamak son derece zordur..." (Platon 1998: 669-d-e) ${ }^{16}$
\end{abstract}

Buna karşılık, Aristoteles'in, sözü müziğin unsurlarından saymamasının, onun Poetika'daki görüşleriyle, bir yönüyle tutarlılık içerisinde olduğu düşünülebilir. Zira, Poetika'da, koro şarkısı içerisinde birbirine eşlik eden iki unsur olarak melodi ve mısra ölçüsünü ( bu anlamda "söz"ü) ve bunların yanında ritmi kullanan sanatlar olarak, dithyrambos şiiri, nomon, tragedya ve komedya sayılmaktaydı. Flüt, kithara ve kaval çalma sanatları ise bu kapsamın dışında tutulmakta, onların yalnızca harmoni ve ritmi kullandığ1 söylenmekteydi. (Aristoteles Ekim 2008, Bölüm 1.4-5) Dolayısıyla, her ne kadar "ses aracılığılla taklit eden sanatlar" kategorisinde sayılıyorsa da, bu son saydıklarımız "söz" aracını kullanmıyor sayılmaktadır. Bu yönüyle makul görünmekle beraber, Aristoteles, Politika'da, "söz" unsurunu tam olarak konu dışı bıraktığı söylenemez. Zira, çalgısal müzik yanında, şarkı söylemek de eğitim bağlamında incelenmektedir: “...Ozanlar, Zeus'u kendisi çalgı çalıyor (kitharizei/kithara çalma) ya da şarkı söylüyor (aedei) diye anlatmazlar. Gerçekten, profesyonel müzikçileri aşağ sınıftan sayarız; ama bir adam da kendi zevki için ya da bir toplantıda çok içki içince çalgl çalabilir ve söyleyebilir." (Aristoteles 2000: 1339-b)

14 Yine aynı diyalogda, 656-c ve 668-b numaralı pasajlarda Türkçeye "söz" olarak çevrilen rhema/rhematos terimleri kullanilmakta. (Platon 1962: 398-c)

Şölen'de ise, şöyle bir tanım verilmektedir: “...müzik (mousikē) , harmoni (harmonian) ve ritim(rhuthmon) alanında sevgi olaylarının bilgisidir.” (Platon 2006: 188c) Yine aynı tanım, Yasalar 655a'da geçmektedir. Burada bir karşıtlıtan ziyade benzerlik mevcuttur: Şölen'de müzik, bir bilgi konusu iken, Devlet'te somut bir müzik eseri olarak melostan bahsedilmektedir.

16 Devlet'te bu farklılık açıkça şu şekilde geçmekte: "Böylesi ritimler bulunca, ölçü de, melodi de söze uyacak. Söz, ölçü ve melodiye değil. (Platon 1962: 400a) 
Son olarak, Poetika ve Politika arasındaki bir başka fark, ritim unsurunun ele alınışı açısındandır. Poetika'da "şiirdeki ölçünün ritmin bir türü olduğundan""17 söz edilmekte, özel olarak da, komedya ve tragedyanın gelişimindeki yeri açısından, trimetre (jambik), tetrametre (trokhaik) ve hexametre (heroik) vezin kalıpları incelenmekte, fakat veznin öykü karşısında ikincil önemde olduğu söylenmekteydi. (Ekim 2008: Bölüm 4; 9.7) Politika'da ise ritimler, yalnızca, harmonileri ayıran ahlaki nitelikler açısından kategorize edilmekteydi: “...bazı ritimlerin durultucu etkisi vardır, bazıları denge bozucu, bu ikincilerden bazıları bayağı hareketlere yol açar, bazıları soylu hareketlere." (2000: 1340-b) Buna karş1lı, Platon'un Devlet'te ritimler üzerine daha teknik bir açıklaması vardır; o burada ritimlerin isimlendirilmelerinin hangi ölçüte göre yapıldı ğından ve onların kullanılış şekillerinden bahseder. Fakat, burada adı geçen ritimler, hece ölçüsü olarak şarkının prozodisinde ritim görevi yaparlar; aynı matematiksel ölçünün hem müzikal ritme hem de vezne uygun olması beklenir. (Plato 1903: 400b) ${ }^{18}$ Platon bunu şu şekilde açıklar: "Böylesi ritimler bulunca, ölçü de, melodi de söze uyacak. Söz, ölçü ve melodiye değil.” (Platon 1962: 400-a) O halde, ritim unsurunun, gerek Platon, gerekse Aristoteles tarafindan, söz ve ezginin birbirine eşlik ettiği şarkı içerisinde, prozodi açısından kullanımıyla ilgisinde ele alındığı açıktır. $\mathrm{Bu}$ konuda, Aristoksenus da aynı çizgiyi takip etmektedir. O, ritim unsurunu kuramsal müziğin 7 öğesi içerisinde saymamakta, ritmi hece ölçüsüyle birlikte, ayrı bir kitabın konusu yapmaktadır. ${ }^{19}$

\section{Sonuç}

Burada incelediğimiz temel müzik terimlerinin antik kullanımlarında, görüş farklılıkları ayrı tutulmak üzere, asgari terminolojik tutarlılık görülmektedir. Bununla birlikte armoni, melodi ve ritim gibi kimi temel terimlerin günümüzdeki kullanımlarıyla yer yer kimi uyuşmazlıklar tespit edilmiş; bu uyuşmazlıkların müzikolojik bağlam, tarihsel koşullar ve dönemin bilimsel kapasitesi ile ilgileri belirlenerek çözüme yönelik kimi terminolojik öneriler sunulmuştur.

17 Retorik 3. kitabın 8. bölümünün girişinde görüldüğü gibi, nazım türleri dışında da, nesirde de bir tür ölçüden (metros) söz edilmektedir. (Aristoteles Mart 2008, Kitap 3, Bölüm 8)

Şölen'de de, bu fikri destekleyecek şu ifadelere rastlarız: “...insanların harmonileri ve ritimleri kullanışlarında gerek müzik yaratırken (buna besteleme diyoruz), gerek bu yaratılan ses ve söz düzenlerini [melesi] (ki buna da usul bilgisi-metrois- deriz)...” (Platon 2006: 187cd)

19 Pearson, Lionel, Aristoxenus: Elementa Rhythmica. The Fragment of Book II and the Additional Evidence for Aristoxenean Rhythmic Theory, Clarendon Press, Oxford, 1990, Index. Yine de bu açıdan ritmin ikincil bir öneme sahip olarak düşünüldüğü sonucunu çıkarmamalıyız. Zira, ritim, zamansal art ardalık yönünden müziğin anlaşılmasının temel koşulu, belki de bu açıdan müziğin olmazsa olmaz unsurudur. 


\section{KAYNAKÇA}

AGNEW, Vanessa (2008). The Power of Music in Other Worlds, New York: Oxford University Press.

ANONYMOUS (1995). Musica Enchiriadis and Scolia Enchiriadis, Translated by Claude V. Palisca, London: Yale University Press.

APEL, Willi (1974). Harvard Dictionary of Music, Cambridge, Massachusetts: The Belknap Press of Harvard University Press.

ARİSTOTELES (1996). Metafizik, çev. Ahmet Arslan, İstanbul: Sosyal Yayınları.

ARİSTOTELES (Ekim 2008). Poetika, çev. İsmail Tunalı, İstanbul: Remzi Kitabevi.

ARİSTOTELES (2000). Politika, çev. Mete Tunçay, İstanbul: Remzi Kitabevi. Yayınlar1.

ARİSTOTELES (Mart 2008). Retorik, çev. Mehmet H. Doğan, İstanbul: Yap1 Kredi

ARISTOTLE (1996). Ars Poetica, Edited by R. Kassel, Oxford: Clarendon Press.

ARISTOTLE (2002 On Poetics, Translated by Seth Benardete and Michael Davis, South Bend, Indiana: St. Augustine’s Press.

ARISTTOXENUS, Tarentum (1902). The Elements of Harmony, Translated by Henry S. Macran, Oxford: Clarendon Press.

AUDI, Robert (1999). The Cambridge Dictionary of Philosophy, Second Edition, Cambridge: Cambridge University Press.

BLACKBURN, Simon (1996). The Oxford Dictionary of Philosophy, Oxford: Oxford University Press.

BURNEY, Charles (1978). A General History of Music, Volume I, New York: Harcourt, Brace and Company.

BURNEY, Charles (1957). A General History of Music, Volume II, New York: Dover Publications, Inc.

COLLECTIVE (2006). Blackwell Companions to Philosophy, A Companion to Ancient Philosophy, Edited by Mary Louise Gill and Pierre Pellegrin, Oxford: Blackwell Publishing.

COLLECTIVE (1999). Routledge History of Philosophy, Volume II, From Aristotle to Augustine, Edited by, David Furley, New York: Routledge Press.

COLLECTIVE (1999). The Cambridge Companion to Aristotle, Edited by Jonathan Barnes, Cambridge: Cambridge University Press.

COLLECTIVE (2006). The Cambridge History of Western Music Theory, Edited by Thomas Christensen, Cambridge: Cambridge University Press.

ERAYDIN, Müge (2006). Müziğin Doğasında Varolan Fizik ve Matematik Öğelerinin Çăgdaş Teoremler İçerisinde Incelenmesi, İstanbul: Y.Ö.K. Ulusal Tez Merkezi.

GROTE, George (2004). Plato and Other Companions of Socrates, Volume III, London: Elibron Classics.

KATZ, Ruth and DAHLHAUS, Carl (1987) Contemplating Music, Source Readings in the Aesthetics of Music, Volume I: Substance, New York: Pendragon Press. 
MAHTHIESEN, Thomas J. (2006). Greek Music Theory, in The Cambridge History of Western Music Theory, Edited by Thomas Christensen, Cambridge: Cambridge University Press. Press.

NETTLES, Barrie (1987). Berklee College of Music, Harmony, Volume I-IV, Berklee

PEARSON, Lionel (1990). Aristoxenus: Elementa Rhythmica. The Fragment of Book II and the Additional Evidence for Aristoxenean Rhythmic Theory, Oxford: Clarendon Press.

PETERS, E. Francis (2004). Antik Yunan Felsefesi Terimleri Sözlüğü, Çeviren ve Hazırlayan: Hakkı Hünler, İstanbul: Paradigma Yayıncılık.

PLATO (1903). Platonis Opera, Edited by John Burnet, Oxford: Oxford University Press. Kitabevi.

PLATON (1962). Devlet, çev. Sabahattin Eyüboğlu, M. Ali Cimcoz, İstanbul: Remzi

PLATON (2006). Şölen, Dostluk, çev. Sabahattin Eylüboğlu, Azra Erhat, İstanbul: Türkiye İş Bankası Kültür Yayınları. Yayınevi.

PLATON (1998). Yasalar, çev. Candan Şentuna, Saffet Babür, İstanbul: Kabalcı

PRATT, Waldo Selden (1907). The History of Music, A Handbook and Guide for Students, New York: Reprint Services Corp.

ROUSSEAU, Jean-Jacques (2009). Melodi ve Müziksel Taklit ile İlişkisi Iç̧inde Dillerin Kökeni Üstüne Deneme, Çeviren: Ömer Albayrak, İstanbul: Türkiye İş Bankası Yayınları.

SUN, Muammer (2005). Solfej 2, Ankara: Sun Yayınları.

TAGORE, Raja Sir Sourindro Mohu, (1963). Universal History of Music, Volume XXXI, Varanasi: The Chowkhamba Sanskrit Series Office. 